\title{
EL PROCESO DE TOMA DE DECISIONES LEGISLATIVAS. LAS RELACIONES GOBIERNO-PARLAMENTO EN ESPAÑA $(1977-1986)^{*}$
}

\author{
Diego López Garrido \\ (Universidad Autónoma de Madrid) \\ Joan Subirats \\ (Universitat Autònoma de Barcelona)
}

1. Como es bien sabido, las Cortes, Congreso y Senado, representan en España al poder legislativo y ejercen una labor de control de la acción del gobierno. También es sobradamente conocido que las relaciones entre las dos cámaras legislativas españolas configuran a nuestro sistema como un ejemplo más de bicameralismo «imperfecto», en el que el Senado ocupa una posición subsidiaria, tanto por lo que se refiere al proceso legislativo como al proceso de formación y control del gobierno.

Esta situación ha provocado que sea el Congreso de los Diputados el que cuente con la presencia de los principales líderes políticos del país y, al mismo tiempo, el que haya atraído hasta ahora la mayor atención de Ios medios de comunicación. El Senado, en cambio, ha ido reforzando su posición marginal y dependiente, hasta el punto de ser hoy uno de los principales focos de atención en posibles reformas institucionales (pasen éstas por la vía de modificación del texto constitucional o por una más simple reelaboración reglamentaria). La composición de las Cortes Generales en las sucesivas legislaturas demuestra que el Senado repite la composición política del Congreso, ampliando si acaso la mayoría política resultante. Ello convierte el proceso legislativo en repetitivo y el paso de los proyectos y proposiciones de ley por la Cámara Alta no acostumbra a introducir elementos de novedad importante.

* Este artículo es la versión castellana, ligeramente retocada, de un precedente trabajo en lengua inglesa próximo a aparecer en un libro colectivo sobre Parlamentos en el Sur de Europa a publicar en Francis Pinter bajo la coordinación de UIrike Liebert.

Papers 33 (1990) (35.49) 
2. Durante las dos primeras legislaturas democtáticas, el grupo de UCD gozó de mayoría en ambas cámatas. Como se ha venido repitiendo, fue la diversidad ideológica y el choque de personalidades las que, junto a una mala gestión económica, condujeron al partido de UCD a la desintegración después de la aparatosa derrota de 1982. La actividad parlamentaria de ese período venía también muy condicionada por la necesidad de los centristas de pactar cada una de las decisiones de las cámaras con diversos grupos (sobre todo populares y convergentes) a fin de conseguir la mayotía absoluta de la que no disponían. Esa situación agravaba aún más las discrepancias internas en un partido que agrupaba desde conservadores a socialdemócratas.

Esa situación contrasta con la que se ha venido produciendo desde 1982. Como es notorio, desde las elecciones de octubre de ese año, el grupo socialista ha dispuesto de mayoría absoluta en ambas cámaras y, superada la crisis de liderazgo de 1979, ha mantenido una fuerte centralización de su ditección, personalizada en las figuras de González y Guerra.

3. Es también obligado mencionar el hecho de que el parlamento español, a diferencia de lo que ocurre en otros entornos, no se ha destacado en estos años por una gran capacidad de integración o articulación de intereses sociales, ni tampoco por constituir uno de los núcleos centrales de atención del gran público. Los partidos en España, aparte de pasat por diversas crisis, no han llegado a estructurar militancias potentes, ni tan sólo han mantenido grados de frabilidad notable en las elecciones de los diferentes niveles de gobierno. El gtado de socialización política ha sido - y es-m bajo, y el grado de articulación social se sitúa también por debajo de países con tradiciones liberal-democtáticas más afianzadas. En ese contexto, podríamos afirmar que la vía consensual de elaboración y aprobación de la nueva Constitución, si bien facilitó una transición no traumática, no ayudó, por su secretismo y falta de transparencia, a mantener los altos niveles de politización de los primetos tiempos de la transición.

4. Este conjunto de elementos, aquí muy sumariamente expuestos, constituyen el telón de fondo en el que considerar el proceso de elaboración, discusión y aprobación de los textos legislativos en el período considerado, así como las relaciones entre el gobierno, su grupo parlamentario y el conjunto de las cámaras.

La falta de unidad de la UCD se reflejaba en la poca fluidez en las relaciones en el interior del ejecutivo, así como en el proceso de discusion del ejecutivo con el grupo parlamentario centrista. Existían claras conexiones entre distintos miembros del gabinete y parlamentarios del grupo 
centrista, pero ello servía de poco dada la falta de unidad interna del gobierno y del grupo parlamentario. Los distintos ministerios y cargos de responsabilidad política se habian ido repartiendo entre las distintas «familias» centristas, lo cual provocaba desconexiones evidentes entre el presidente de Gobierno, el secretario general de UCD y el portavoz parlamentario del grupo centrista.

\section{FIGURA 1}

Gobierno UCD: esquema de relación de los sujetos parlamentarios

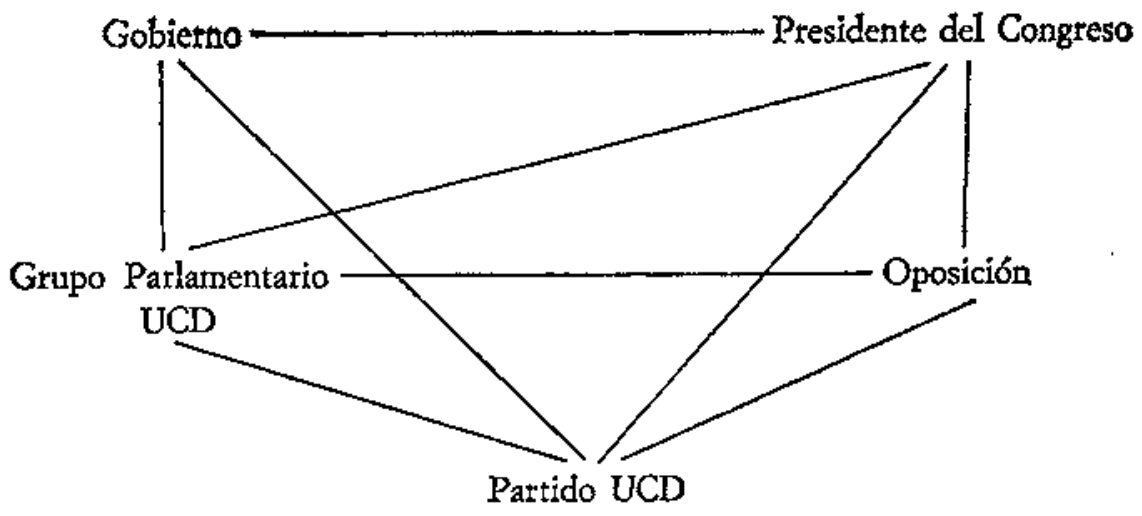

Fuenre: Lópes Garrido (1985), p. 235.

De esta forma, un tepaso a la actividad legislativa durante este período revela una clara falta de cohesión (ver figura 1). Cada ministro buscaba en «su» grupo parlamentario, «su» portavoz para que defendiera «su» proyecto de ley. Se intentaron evitar de forma deliberada las discusiones o debates generales entre el gobierno y el grupo patlamentatio, con la intención de no hacer explícita la gran fragmentación existente. Sólo cuando las diferencias eran tan claras que parecían poner en peligro la viabilidad patlamentatia de algún proyecto de ley, se entablaban negociaciones formales entre el ejecutivo y su grupo parlamentario (ése fue el caso de los distintos proyectos de reforma universitaria, de la ley de divorcio o, incluso, del proyecto de presupuestos de 1981). Por otro lado, la ya mencionada falta de mayoría absoluta obligaba a un continuo proceso de negociación con grupos parlamentarios más o menos afines. Y ello introducía nuevos factores de tensión en el partido, ya que las diferentes "familias» se acusaban mutuamente de hacer demasiadas concesiones a, según los ca- 
sos, derecha o izquierda. Todo ello daba alas a una oposición que, con estos fundamentos, podía acusar de falta de consistencia y de resolución a la política gubernamental centrista. Así, Suárez o Calvo Sotelo fueron encontrando numerosas dificultades para dirigir al pás, atrapados en constantes problemas internos de partido y acosados continuamente por la oposición.

5. Durante el período de gobierno socialista, los mecanismos de decisión política han sido tan diferentes del período centrista como to ha sido la situación política de partida. Mientras UCD estaba dividida en numetosas «familias» o facciones, el PSOE ha mantenido un alto nivel de centralización, con una posición indiscutida e indiscutible de sus principales dirigentes, el secretario general y vicesectetatio general. Felipe González y Alfonso Guerra ocupan esos puestos, siendo al mismo tiempo el presidente y vicepresidente del gobierno socialista en todos estos años. Su posición se ha visto también reforzada por el hecho de que durante estos años se hayan dado muy pocos casos en los que se haya dado esa duplicidad de ejercicio de funciones en el Comité Federal del partido y en el Gobierno.

\section{Figura 2}

Gobierno PSOE: esquerra de relación de los sujetos parlamentarios

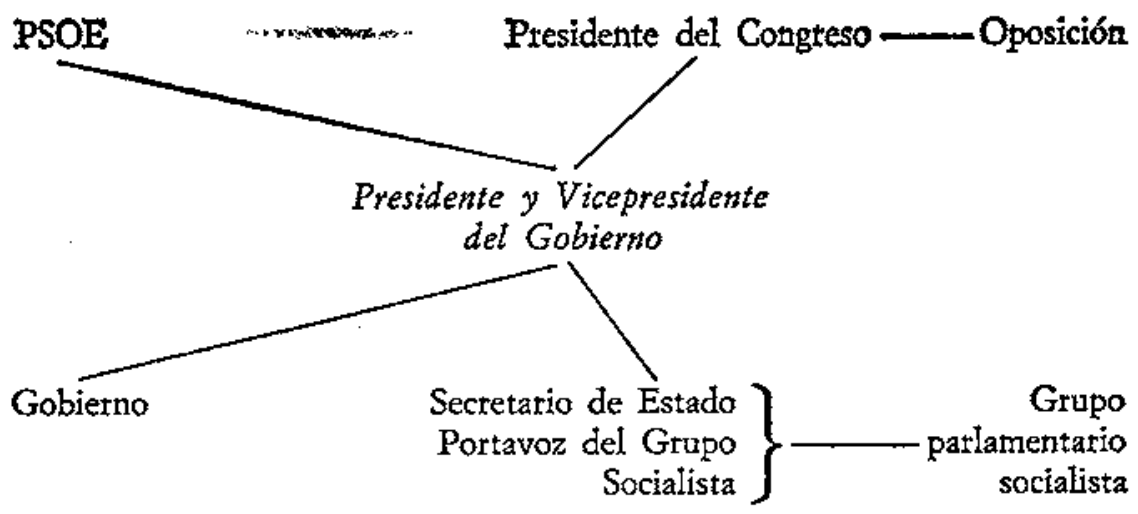

Fuente: López Gatrido (1985), p. 242.

- Si observamos el nudo de relaciones entre gobierno socialista y Parlamento, y más concretamente las relaciones gobierno-grupo socialista (ver 
figura 2) las diferencias con ei período centrista son aún más claras. Cada proyecto de ley elaborado por el Gobierno, es primeto discutido por el ministro o ministros afectados por el nuevo diseño legislativo y los miembros del grupo parlamentario que están más especializados en el tema en cuestión. De esas teuniones surge un acuerdo sobre las posibles enmiendas a introducir, siendo siempre decisiva, en caso de desacuerdo, la opinión del presidente o vicepresidente del Gobierno. De esta forma, las posiciones conjuntas entre Gobierno y grupo parlamentario socialista se mantienen sin problemas durante el procedimiento legislativo, asegurando la disciplina y lealtad del grupo parlamentario, pero asegurando también la confianza del Gobierno en el trabajo de los parlamentarios socialistas.

Todo ello confirma el papel central de las dos principales figuras del partido y del Gobierno en el conjunto del proceso decisorio del período socialista. Centralización que se ha visto reforzada desde junio de 1986 al anunciarse la decisión de que, a partir de esa fecha, Alfonso Guerra iba a presidir la reunión de subsecretarios de los distintos ministerios, reunión siempre previa y preparatoria del Consejo de Ministros. De esta manera se pone más de relieve el papel clave del vicepresidente y vicesecretario general en el control del entero proceso de toma de decisiones. Partido, Gobierno y actividad parlamentaria convergen y se interseccionan en las dos figuras clave, González y Guerra que, por lo demás, patecen mantener una estrecha y latga amistad.

6. Repasemos ahora lo que ha sido el balance del proceso de iniciativa legislativa en el período considerado. Como es sabido, los proyectos de ley son, por definición, de origen gubernamental, mientras que las proposiciones de ley pueden tener su origen en algún grupo parlamentario, sea del Congreso o del Senado, en las comunidades autónomas o a través del procedimiento denominado de iniciativa popular. 
Cuadro 1

Origen de las iniciativas legislativas

\begin{tabular}{lccccc}
\hline & \multicolumn{2}{c}{ 1979-1982 } & & \multicolumn{2}{c}{$1982-1986$} \\
\cline { 2 - 6 } & Introducidas & Aprobadas & & Introducidas & Aprobadas \\
\hline Proyectos de ley .............. & 287 & 207 & 200 & 183 \\
Proposiciones ley Congreso & 200 & 33 & 109 & 13 \\
Proposiciones ley Senado .... & 7 & 6 & 1 & 1 \\
Proposiciones ley comunida- & 1 & - & 17 & 6 \\
$\begin{array}{l}\text { des autónomas ............ } \\
\text { Iniciativa legislativa popular }\end{array}$ & - & - & 3 & - \\
\hline
\end{tabular}

FUENre: Elaboración propia a partir publicaciones Cortes Generales,

Como puede comprobarse en el cuadro adjunto (ver cuadro 1), es el Gobierno el que ha mantenido un claro predominio en relación al origen de las propuestas normativas. Si en la primera legislatura (1977.1979), la propiamente constituyente, el número de leyes aprobadas con origen parlamentario fue de un 9 por ciento, el porcentaje subió a un 16 por ciento en la siguiente legislatura (1979-1982). Ese notable aumento, que resulta incluso inusual en perspectiva comparada, podría tener su explicación en difetentes factores: la acentuación de Ia fragmentación interna de UCD en esa legislatura y por tanto su mayor debilidad; el fin de la fase «consensual» o de "transición» que había caracterizado el período anterior; y Ia disminución de la capacidad de iniciativa de UCD en la última fase de esta legislatura. En la legislatura siguiente (1982-1986), de predominio socialista, el número de leyes aprobadas con origen en el Parlamento volvió a descender a menos de un 6 por ciento, lo que sin duda cabe achacar a la indiscutible mayoría socialista y a la centralización de su proceso decisional.

Puede asimismo observarse que los proyectos de ley (por tanto de origen gubernamental), tienen muchas más posibilidades de convertirse en ley que las proposiciones de la ley. Los proyectos de ley no sufren en Es. paña ningún tipo de restricción, y una vez presentados por el Gobierno se procede a su tramitación parlamentaria y a la preceptiva presentación de enmiendas por parte de los parlamentarios y sus grupos. No se da en España un período de información pública, ni un cierto proceso de consulta formal con aquellos sectores presumiblemente afectados por la ley, ni tampoco interviene el Senado (dada su condición de cámara de representación territorial) para considerar, por ejemplo, si ese proyecto puede afectar a las comunidades autónomas. A pesar de ello, y como confirmación 
de comentarios anteriores, podemos ver cómo en el período centrista (1979. 1982) llegaton a la condición de leyes el 72 por ciento de los proyectos presentados, mientras que en la primera legislatura socialista el porcentaje llegó al 91,5 por ciento.

7. Las proposiciones de ley presentadas por los distintos grupos parlamentarios han de superar la fase denominada de «toma en consideración», en la cual el pleno decide si acepta o no su posterior tramitación en el Congreso. Parece obvio que el grupo mayoritario tiene en la «toma en consideracións un formidable instrumento para cercenar la capacidad de iniciativa de los grupos que no forman parte de la mayoría de gobierno. Las razones para oponerse a la tramitación de alguna proposición de ley pueden sustentarse en la afirmación de que el Gobierno está preparando precisamente un proyecto legisiativo sobre la materia, o simplemente sobre la inoportunidad o desacuerdo con la filosofía de la proposición. Resulta también evidente que ésta puede ser una buena oportunidad para el Gobierno de pactar con grupos de la oposición ciertas contrapartidas a cambio de un nibil obstat a la proposición de ley. En la legislatura 1979. 1982, el 32 por ciento de las proposiciones de ley introducidas por los distintos grupos parlamentarios fueron aceptados en la fase de «toma en consideración», mientras en la legislatura 1982-1986 sólo se aceptaton el 15 por ciento de tales proposiciones de ley. Esto puede volver a ser ilustrativo del decreciente papel de la oposición parlamentaria al pasar de un gobierno de mayoría relativa a un gobierno de mayoría absoluta.

8. Si profundizamos un poco más en los aspectos de iniciativa legislativa, y nos detenemos en cómo han respondido los distintos grupos parlamentarios (ver cuadro 2) en las dos legislaturas consideradas, observamos una drástica reducción del número de proposiciones de ley presentadas en el período 1982-1986. La razón principal de tal descenso cabe buscarla en la pérdida de protagonismo del principal grupo de la oposición en uno y otro período. Mientras el grupo socialista presentó 84 proposiciones de ley entre 1979 y 1982, el grupo de Alianza Popular sólo introdujo 48 entre 1982 y 1986 . Otra característica que destaca es la tremenda reducción de las proposiciones de ley presentadas por más de un grupo parlamentario. Mientras en la legislatura $1979-1982$ se presentaton 44 proposiciones de ley por dos o más gxupos parlamentarios, en el periodo 1982-1986 el número de tales proposiciones descendió a 4 . 
Cundro 2

Proposiciones de ley presentadas y tramitadas

\begin{tabular}{|c|c|c|c|c|c|c|}
\hline & \multicolumn{3}{|c|}{$1979-1982$} & \multicolumn{3}{|c|}{$1982-1986$} \\
\hline & Int. & T.c.* & Aprob. & Int. & T. c.* & Aprob. \\
\hline PSOE & 83 & 23 & 10 & 5 & 5 & $4 * *$ \\
\hline PCE $\ldots \ldots$ & 32 & 7 & 3 & 22 & 3 & $3 * *$ \\
\hline Minoria Catalana ......... & 15 & 7 & 4 & 23 & 3 & 2 \\
\hline Grupo Popular ............. & 11 & 7 & 2 & 48 & 2 & 2 \\
\hline Varios grupos $\quad \ldots \ldots \ldots \ldots$ & 44 & 12 & 9 & 4 & 2 & 2 \\
\hline UCD $\ldots \ldots \ldots+\ldots \ldots$ & 15 & 8 & 5 & - & - & - \\
\hline Minoría Vasca $. . . . . \ldots . . .$. & - & - & - & 6 & 1 & 1 \\
\hline Total & 200 & 64 & 33 & 108 & 16 & $13 * *$ \\
\hline
\end{tabular}

* Toma en consideración.

*t Una de las proposiciones de ley que pasaron fue el resultado de la adición de dos pro. posiciones similares introducidas, respectivamente, por comunistas y socialistas.

Fuexie: Elaboracion propia a partix de publicaciones de las Cortes Generales.

No podemos dejar de destacar asimismo la poca capacidad de iniciativa legislativa del grupo Minoría Vasca, que agrupa a los parlamentarios del PNV, que entre 1977 y 1982 no presentaron ni una sola proposición de ley. Ésa quizá sea una muestra de una cietta automarginación de la vida parlamentaria española, y una concentración absoluta en la negociación directa con la administración central. En la última legislatura la situación parece cambiar, ya que el grupo Minoría Vasca llegó a presentar 6 proposiciones de ley, mostrando pues una mayor integración en la arena política parlamentaria del Estado.

En el caso de las iniciativas surgidas del Senado la reducción ha sido también notoria. Si en la legislatura 1979-1982 se llegaron a presentar 7 proposiciones de ley, en la última legislatura (1982-1986) sólo se presentó una. Ese retroceso demuestra una vez más la situación de cuasimarginalidad del proceso político y legislativo en el que está envuelta la cámara alta del parlamento español.

Las comunidades autónomas pueden también presentar proposiciones de ley. Si en la legisłatura 1979-1982 sólo se presentó una propuesta de este tipo por parte del Parlamento catalán, en la siguiente se presentaron hasta un total de 17 proposiciones de ley, con un buen nivel de éxito si lo comparamos con el obtenido por las iniciativas de origen parlamentario. Finalmente, sólo tres proposiciones de ley fueron propuestas en la legis- 
latura 1982-1986 por la vía denominada de «iniciativa popular», y en ningún caso superaron la primerísima fase de su tramitación, es decir, su aceptación por parte de la Mesa del Congreso.

9. En las dos primeras legislaturas (1977-1979 y 1979-1982), la fase llamada de «ponencia» fue propiamente la fase decisiva del proceso legislativo. Como es notorio, forman la ponencia un pequeño número de diputados, representativos de los diferentes grupos, miembros de la comisión parlamentaria que ha recibido el proyecto o proposición de ley. El número de miembros oscila entre cuatro y diez, dependiendo de la importancia de la propuesta legislativa o de su potencialidad polémica. Su papel no se limita a ordenar las enmiendas presentadas, sino que pueden variat el texto remitido a la comisión inspirándose libremente en el espíritu o la letra de alguna de esas enmiendas. De esta manera, el documento o informe de la ponencia fue constituyendo un texto sustancialmente diferente del presentado en la comisión, texto que contaba, por lo general, con el respaldo de los portavoces en la comisión de los principales grupos de la cámara. Uno de los factores decisivos que puede explicar tal protagonismo es el elemento de discreción que rodea el funcionamiento y los debates de la ponencia. Es precisamente esa característica, excepcional por otra parte en todo el proceso legislativo, la que fue permitiendo a los distintos grupos negociar y hacerse concesiones mutuas sin miedo a tenet que afrontar ante la opinión pública las consecuencias de tales transacciones.

Un examen más profundo de la práctica legislativa durante la legislatura centrista de 1979 a 1982 revela que la ponencia fue, sin duda alguna, la fase más decisiva del conjunto del proceso legisłativo. En algunas leyes más polémicas o que habían despertado más controversias, la fase de ponencia acaparó más tiempo que todo el testo de fases del proceso legislativo, incluida la fase de debate en el Senado (así, por ejemplo, la discusión del proyecto de ley de divorcio, o el código de justicia militar). No obstante, es indudable que en ese protagonismo fue determinante la falta de mayotía absoluta de UCD.

De hecho, después del triunfo socialista en las elecciones de 1982, la ponencia ha ido dejando de ser tan determinante como en las etapas anteriores. Ya no es el lugar privilegiado de consensus-building, porque de hecho esa negociación y acuerdo no resultan imprescindibles para la mayoría gobernante. Los proyectos de ley llegan al parlamento muy «acabados», tras una fase de consulta informal y política realizada en cada ministerio. 
10. En el período aquí considerado, la fase de comisión no ha jugado un papel muy relevante en el proceso legislativo general. Durante la fase 1977-1982, de hecho, la labor de la comisión quedaba «comprimida» entre la decisiva fase de ponencia y la mucho más visible políticamente del pleno. De esta forma, los debates en comisión adquirían poca relevancia. A pesar de ello, como es sabido, las comisiones disponen de competencia legislativa plena para buen número de materias. En la etapa de la legislatura 1979-1982 fueton aprobadas directamente en comisión un total de 46 proyectos o proposiciones de ley, mientras que ese númeto aumentó notablemente (dada la reforma del reglamento de las cámaras en 1982 que potenciaba esa posibilidad) en la legislatura 1982-1986, 1legando a ser definitivamente aprobados en comisión un total de 74 proyectos o proposiciones de ley. Hemos de indicar, no obstante, el limitado alcance de muchas de esas propuestas legislativas, dada la limitación material que impone la misma Constitución a esa forma de delegación de poderes del pleno a la comisión.

11. La fase del pleno en el procedimiento legislativo es sin duda la que más lega al gran público. La presencia, en algunos casos, de los medios de comunicación más potentes resulta primordial para comprender la importancia de la sesión plenaria. Están allí presentes los protagonistas y líderes políticos más conocidos, y todo ello le da una relevancia especial. Durante la fase 1977-1982 era en los momentos de sesión plenaria en los que podían "desatascatse» días y días de discusiones y debates sin fin en fases anteriores. La relación directa y simultánea de los principales líderes políticos y la falta de mayoría absoluta del grupo parlamentario del Gobietno permitía que, en determinados casos, las enmiendas in voce o «transaccionales» fueran instrumentos de última hora para salvar ciertos textos o llegar a compromisos que parecían imposibles. También en este sentido la situación posterior, con un grupo que gozaba de respaldo suficiente para tirat adelante sus decisiones, ha teducido mucho el protagonismo de esa fase.

12. El Senado, como ya avanzábamos, ha jugado hasta ahora un papel muy limitado en el sistema parlamentario español. A pesar de que formalmente sea ésta una cámara de representación territorial, en la práctica se ha ido convirtiendo en un mero duplicado, sin capacidad decisoria en última instancia, del Congreso de los Diputados. Hemos ya mencionado su pequeño protagonismo en la iniciativa legisłativa, y deberíamos añadir que su capacidad de control del ejecutivo es muy débil y poco utilizada. No tiene en sus escaños a personajes políticos de telieve (con la excepción 
no buscada de Hernández Mancha en los últimos años), ni tampoco acuden a sus sesiones los ministros si no deben responder directamente a cuestiones que se les han planteado. Los mismos senadores deben acudir al Congreso si quieren ejercer una cierta capacidad de presión y de relación con los altos cargos y políticos más influyentes. En definitiva, el Senado está, por ahora, situado en la periferia del verdadero binomio de poder institucional y político del sistema: Congreso y Gobierno.

El papel subordinado del Senado se pone aún más de relieve si recordamos las limitaciones formales que tiene pata intervenir en el proceso de discusión y aprobación de las leyes. Sólo se le permiten dos meses para cumplir su labor de relectura y discusión de los textos previamente aprobados por el Congreso; labor que sólo será provisional, ya que la última palabra la tendrá siempre el Congreso. En el caso en que el Congreso decide que el texto debe tramitarse de manera urgente, entonces el tiempo a disposición de la cámara alta se reduce drásticamente a 20 días. Con ese «timing», la labor correctora o revisora del Senado tesulta casi imposible, ya que no puede seriamente reflexionar sobre los proyectos o «aparcar» aquellos aspectos más polémicos para una posterior discusión. En la práctica sólo se puede permitir correcciones técnicas, eliminar solapamientos o introducir aquellas rectificaciones que desde el grupo de la mayoría se quieran tardíamente incorporar. De hecho, durante Ia fase 1979-1982 sólo un 30 por ciento de las leyes fueron modificadas por el Senado después de su aprobación por el Congreso. En la fase posterior, 1982-1986, el número de leyes modificadas ha subido al 50 por ciento, aunque ello no implique cambios sustanciales con lo ya expuesto. Ese aumento de "protagonismo» parece proceder de la voluntad del grupo parlamentario socialista de aprovechar la fase, menos visible, del Senado, para introducir aquellas enmiendas que no habían sido presentadas en el Congreso, o para mejorar a posteriori (dada la cierta difusión que su aptobación en la cámara baja proporciona) los textos legislativos que más repercusiones tienen o pueden tener.

Como ahora ya parece evidente para el mismo gobierno socialista, la única forma en que probablemente el Senado puede mejorar su posición en el sistema político español setía reforzando su papel de cámara de las autonomf́as, actuando como instancia de mediación entre comunidades autónomas y gobierno central, y sirviendo de filtro pata aquellas leyes de la administración central que puedan afectar a las competencias y funciones de las autonomías.

13. Sería preciso referimos, aunque fuera de manera sumaria, al papel de los diputados individuales en el funcionamiento parlamentario. Se 
ha querido traducir el término backbencher por el de «diputado llave», haciendo referencia a la labor meramente ratificativa (girar la llave del sistema de votación y votar) de las decisiones tomadas por los dirigentes del grupo parlamentario de acuerdo con las directrices del Gobierno. Es evidente que desde la fase constituyente se quiso reforzar el papel de los partidos en España, dada su debilidad y falta de enraizamiento. Las posiciones reticentes en relación a los instrumentos de democracia directa o semidirecta, o la partidificación posterior de los procesos electorales así parecen demostratlo. En la vida parlamentaria, el diputado individual tiene muy pocas posibilidades de intervención autónoma, y el control de los dirigentes del grupo es notorio. Los reglamentos internos de los distintos grupos prevén importantes sanciones (políticas y económicas) si no se asisten a las sesiones o se desatienden Ias instrucciones del grupo. En los últimos tiempos, y a pesar de las decisiones de los Tribunales al respecto, se ha pretendido testringit también la posibilidad de cambio del grupo de los diferentes parlamentarios. Todo ello ha conducido a un debilitamiento, quizás inevitable, de la autonomía individual de cada parlamentario.

14. No parece posible sacat de estas notas conclusiones muy relevantes o decisivas. De hecho, hemos examinado de manera sumaria y con voluntad crítica los primeros diez años de funcionamiento democrático de un Parlamento, después de decenios y decenios de autoritarismo y de graves confictos. Sólo la continuidad de estas reflexiones podrá permitirnos una mayor profundidad y consistencia en el análisis de tendencias aquí esbozado. De lo hasta ahora mencionado, podríamos deducir que durante la fase 1979-1982, la primera legislatura propiamente constitucional, el papel del Parlamento en el proceso político español fue relativamente importante e influyente. Un buen porcentaje de las leyes más significativas aprobadas en esa fase tuvieron su origen en el Parlamento, y además casi todas las aprobadas fueron decisivamente modificadas en la fase de ponencia. Ahora bien, parece claro que la debilidad del Gobierno y la fragilidad ideológica y de liderazgo del partido del Gobierno en esa fase, UCD, la falta de estabilidad del proceso democrático y un cierto mantenimiento de las pautas de consenso del petíodo constituyente permitieron ese inusual protagonismo parlamentario.

La victoria socialista de octubre de 1982 y la consecución de una amplia mayoría absoluta en ambas cámaras modiffcaron sustancialmente ese panorama y el papel del Parlamento en el funcionamiento general del sistema político español. Aparte de la confianza política que proporcionaba la mayoría absoluta, es evidente que también jugó su papel la peculiar 
centralización del proceso decisional, tanto del partido socialista como del gobierno, y la crisis evidente del principal partido de la oposición.

Desde 1982 es el Gobierno el verdadero, y casi único, protagonistat del juego parlamentario. La fuerza y cohesión interna del PSOE y la abrumadora mayoría en ambas cámaras convirtieron al grupo parlamentario socialista en espectador, privilegiado pero espectador, de la relación clave y directa entre Gobierno y oposición en la arena parlamentaria. Una prueba de ello la tenemos en el papel limitado que ha venido jugando el grupo parlamentario socialista en el proceso de elaboración legislativa, en su falta de maniobrabilidad para aceptar enmiendas en plena discusión parlamentaria sin contrastar antes sus posiciones con las del ministerio responsable del texto legislativo en discusión, y en el aumento insólito de la presencia directa de ministros y otros altos cargos en sesiones especiales y comparecencias ante comisiones parlamentarias. En todas estas ocasiones el papeI del grupo mayoritario ha sido poco claro, manteniendo el protagonismo del diálogo con la oposición el mismo gobierno. Todo ello conlleva que sea el gobierno quien mantenga las más altas cuotas de presencia en los medios de comunicación, utilizando al Parlamento y a su papel en el entramado institucional como foro de debate político.

La oposición ha ido perdiendo el papel que tuvo en las primeras legislaturas. Las crisis internas de Coalición Democrática primero, al romperse en sus diferentes componentes ideológicos, el posterior recambio de liderazgo en Alianza Popular, o su recientísima recomposición en el «nuevo» Partido Popular, han ido provocando una sensación de falta de alternativa que se ha hecho notar también en el seno del Parlamento. Si desde 1982 los socialistas intentaron reforzar a la oposición y a su principal líder, confriéndole un estatus parecido al existente en Gran Bretaña, la situación de crisis interna mencionada hizo fracasar la operación y otorgó mayores espacios de maniobra a los demás grupos de la cámara. Pero, en realidad, si como se ha dicho el Parlamento no puede ser sólo un órgano de la mayoría, sino un órgano de la mayoría y de la oposición, podemos afirmar que en la actualidad es más un instrumento del Gobierno para explicar su política que una plataforma de la oposición para demostrar su capacidad de recambio.

No se da en este Parlamento una negociación real (sobre todo en referencia al proceso legislativo) entre grupos patlamentarios distintos que representen diferentes intereses sociales. La negociación real con aquellos grupos o intereses afectados se da al nivel gubernamental, de tal manera que se podría decir que una vez que un proyecto de ley llega a la cámara ese texto ha sido ya previamente discutido y negociado con aquellos sectores más influyentes que podrian verse afectados por el mismo. La oposi- 
ción juega pues, en general, un papel más político que de representación social. Eso podría explicar la pérdida de papel de la oposición y la tnayor arrogancia del Gobierno en el diseño, discusión y aprobación de las leyes. La conclusión parece clata, la relación actual es de gobierno fuerte-parlamento débil. El gobierno es el centro de poder decisional normativo, y es en la instancia gubernamental en la que se articulan o pueden articularse los distintos intereses sociales. El Parlamento se convierte en un trámite necesario. 


\section{REFERENCIAS BIBLIOGRAFICAS UTILIZADAS}

E. Aja, X. Atbós (1980): «El Senado. Cámata posible de las autonomías», Revista de Esiudios Politicos, 17, pp. 38-69.

S. Campo. J. F. Tezanos y W. Santin (1982): «La elite política española y la transición a la democracia», Sistema, 48, pp. 21-61.

J. Esteban, L. López Guerra (1982): Los Partidos Politicos, Barcelona, Planeta.

P. Jover, J. Marcet (1985): «Teoría y tealidad en Ias telaciones del gobieno con el grupo parlamentatio y el grupo mayoritario», en El Gobierno en la Constitución Española, Barcelona, Diputación de Barcelona, pp. 251-273.

J. Linz (1981): «Un secolo di politica e di interessi in Spagna», en S. Berger (ed.), L'organizzazione degli inteyessi in Spagna, Bologna, II Mulino, pp. 477-549.

D. Lopez Garrido (1982): «La posición de las ponencias en el procedimiento legislativo del Congreso de los Diputados», en Revista de Derecho Politico.

- (1985: «Gobietno y Parlamento: dos modelos de relaciones internas», en $E l$ Gobierno..., op. cit., pp. 231-244.

J. M. Maravall (1980): «Transición a la democracia. Alinearnientos políticos y elecciones en España», Sistema, 38, pp. 65-105.

J. M. Maravall (1982): «Introducción», en Parlamento y Democracia. Problemas y perspectivas en los años 80, Madrid, F. Pablo Iglesias, pp. 1-9.

I. Molas, I. Pitarch (1987): Las Cortes Generales en el sistema parlamentario de gobierno, Madrid, Tecnos.

V. Pérez Díaz (1984): «Políticas econórnicas y pautas sociales en la España de la transición: la doble cara del neocorporativismon, España; un presente para el futuro, Barcelona, Planeta, pp. 21-56.

J. Sole Tuta (1982): «Democracia y eficacia en las Cortes Españolas», Parlamento y Democracia..., op. cit., pp. 93-108.

J. Sole Tura, M. A. Aparicio (1985): Las Cortes Generales en el sistema constitucional, Madrid, Tecnos.

J. Subirats (1986): «An approach to the legislative production of the Spanish Parliament (1979-1982)», European Journal of Political Research, 14, pp. 321-338.

J. Subirats (1987): «Monopolio Políttico e Conflitto Sociale», en Micromega, núm. 2, pp. 87-96. 